\title{
ПРОДУЦИРОВАНИЕ АЛЬТЕРНАРИОЛА У ПОПУЛЯЦИЙ МЕЛКОСПОРОВЫХ ВИДОВ Alternaria, АССОЦИИРОВАННЫХ С ЗЕРНОВЫМИ КОРМАМИ
}

\author{
Г.П. КОНОНЕНКО, Е.А. ПИРЯЗЕВА, А.А. БУРКИН
}

Современная наука располагает убедительными доказательствами того, что грибы рода Alternaria представляют серьезную токсикологическую опасность. Благодаря способности активно расти на разных суб́стратах в широком диапазоне температур и влажности они занимают обширную экологическую нишу и продуцируют несколько структурных типов вторичных метаболитов с особо опасными формами негативного действия (S.M. Tralamazza с соавт., 2018). В группе дибензо- $\alpha-$ пиронов наиболее известен альтернариол (АОЛ), обладающий высокой цитотоксичностью, генотоксическим и мутагенным действием (Z. Мао с соавт., 2014). Объем информации относительно способности грибов Alternaria продуцировать этот токсин остается пока ограниченным. За последние годы в России выявлена значительная распространенность мелкоспоровых видов этих грибов на зерновых культурах (Ф.Б. Ганнибал, 2004, 2008; Т.Ю. Гагкаева с соавТ., 2012). Обнаружено возрастание частоты встречаемости и числа случаев значительного накопления АОЛ в зерне и кормовых зерносмесях (Г.П. Кононенко с соавт., 2019, 2020). В настоящем исследовании нами впервые показано, что виды $A$. tenuissima, A. alternata и $A$. arborescens могут иметь отношение к контаминации зерновых кормов этим микотоксином. Целью работы стала оценка потенциала накопления АОЛ основными видами грибов рода Alternaria, ассоциированных с зерновыми кормами. Культуры грибов выделяли из 57 образцов кормов, включая зерно пшеницы, ячменя, кукурузы и овса, семена подсолнечника, отруби пшеничные и комбикорма. Моноконидиальные изоляты, идентифицированные по культурально-морфологическим признакам как A. tenuissima (Nees et T. Nees: Fries) Wiltshire, A. alternata (Fr.) Keissl и A. arborescens E.G. Simmons, а также 14 изолятов, отнесенных к группе видов $\boldsymbol{A}$. infectoria, культивировали на панели из четырех питательных сред, включающей картофельно-морковный агар (potato-carrot agar, PCA), сенной aгap (hay infusion agar, НАY), солодовый агар (malt extract agar, MEA) и овощной агар (vegetable juice agar, V-8), в течение 7 сут при $25^{\circ} \mathrm{C}$. Определение АОЛ в экстрактах образцов биомассы выполняли методом непрямого конкурентного иммуноферментного анализа (ELISA) с помощью аттестованной коммерческой тест-системы. Среди изолятов, принадлежащих групाе видов A. infectoria, 13 были лишены продуцирующей способности, тогда как для одного из них накопление АОЛ наблюдалось на всех ростовых средах в количествах соответственно $2,0 \pm 0,2 ; 14 \pm 3 ; 18 \pm 4$ и $220 \pm 30$ мкг/г. Оценка биосинтетического потенцила $A$. tenuissima и $A$. alternata показала, что по общему числу продуцентов и доле высокоактивных и сверхактивных изолятов наиболышая степень его реализации наблюдается на МЕА. Суммарная величина накопления АОЛ в этих условиях для обоих видов оказалась практически одинаковой и составила соответственно 73 и 71 мкг/г. Изоляты A. arborescens обеспечивали наиболышую продукцию АОЛ на средах V-8, НАY и МЕА в количествах, равных соответственно 106, 64 и 31 мкт/г.

Ключевые слова: альтернариол, Alternaria tenuissima, Alternaria alternata, Alternaria arborescens, группа видов Alternaria infectoria, зерновые корма, иммуноферментный анализ.

Современная наука располагает убедительными доказательствами того, что грибы рода Alternaria представляют серьезную токсикологическую опасность (1). Благодаря возможности активного роста на разных субстратах в широком диапазоне температур и влажности они занимают обширную экологическую нишу и способны продуцировать вторичные метаболиты нескольких структурных типов с особо опасными формами негативного дей-

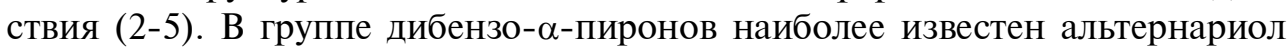
(АОЛ), обладающий высокой цитотоксичностью, генотоксическим и мутагенным действием (6).

Оценка риска контаминации микотоксинами природных объектов, подверженных инфицированию микроскопическими грибами, предполагает поэтапное выполнение комплекса микологических и микотоксикологических исследований. Сначала в выборке образцов, наиболее полно характеризующей объект обследования, идентифицируют основные виды в составе микобиоты, затем данные по токсинообразующей способности 
совокупности изолятов экстраполируют на всю популяцию. Выполнение подобных проектов для зерна в связи с его инфицированием грибами Alternaria предпринималось уже неоднократно для отдельных агроэкосистем в странах Латинской Америки (7-9), Европы $(10,11)$ и Азии $(12,13)$, но сопоставление результатов не всегда возможно из-за неоднозначности подходов к дифференциации видов и различий в условиях экспериментального тестировании грибов. В России потенциал образования АОЛ грибами Alternaria, инфицирующими зернопродукцию, остается практически не изученным, и лишь в одной из работ немецких исследователей приведены данные для 24 изолятов из зерна, собранного с одного поля в Новосибирской области (14).

Следует признать, что трудности, связанные с многообразием приемов установления видовой принадлежности грибов Alternaria, имеют объективный характер. Таксономическая система этого рода в настоящее время находится в процессе совершенствования $(15,16)$. Идентификация по морфологическим признакам признается не всегда однозначной, границы признаков у разных видов перекрываются. Развитие молекулярных методов, а также полифазного подхода, использующего данные метаболического профиля, пока проходит стадию накопления информации (17-19). В связи с этим при оценке биообъектов исследователи все чаще склоняются к выбору традиционного подхода, основанного на совокупности морфологических характеристик репродуктивных структур и характере спороношения при контролируемых условиях (20).

Процедура тестирования токсинообразования грибов in vitro, несомненно, нуждается в унификации. Для этой цели предпочтительно использовать не зерновые субстраты, на которых не всегда достигается необходимая прецизионность определения, а гомогенные агаровые среды. Краткосрочное 7-суточное выращивание грибов при 23-25 ${ }^{\circ} \mathrm{C}$ на таких матрицах с последующим анализом метаболитов в блоках мицелиальноспоровой биомассы широко используется в хемотаксономии родов Penicillium и Aspergillus (21, 22).

В представляемой работе мы впервые количественно оценили способность грибов Alternaria продуцировать АОЛ на панели из четырех питательных сред, рекомендованных для идентификации представителей этого рода, и установили видовые особенности метаболического ответа на тип ростовой среды. Кроме того, впервые показано, что три морфологических вида (Alternaria tenuissima, A. alternata и A. arborescens) могут иметь отношение к контаминации зерновых кормов этим токсином.

Нашей целью стало изучение потенциала продуцирования альтернариола у популяций мелкоспоровых видов грибов рода Alternaria, ассоциированных с зерновыми кормами.

Методика. Первичные культуры грибов Alternaria выделяли из 57 образцов зерновых кормов, относящихся к семи типам: зерно пшеницы (29 образцов), комбикорма (12 образцов), зерно ячменя (7 образцов), семена подсолнечника (6 образцов), отруби пшеничные, зерно кукурузы и овса (по одному образцу). Видовую принадлежность грибов определяли по культурально-морфологическим признакам в соответствии с описанием (23). Моноконидиальные культуры Alternaria tenuissima (Nees et T. Nees:Fries) Wiltshire, A. alternata (Fr.) Keissl и A. arborescens E.G. Simmons получали, используя конидиальные взвеси в $0,1 \%$ стерильном растворе Tween 80 . Контролируя число конидий в одной капле диаметром 0,4 см, вносили 3-4 капли в стерильные чашки Петри, заливали их тонким слоем расплавленного и охлажденного агара Чапека-Докса и культивировали в течение 1 сут при 23$25{ }^{\circ} \mathrm{C}$. Участки агара с одиночными проросшими конидиями после про- 
смотра под микроскопом переносили на скошенный агар Чапека-Докса.

Выборки культур грибов каждого вида для тестирования формировали по принципу 1 изолят - 1 проба. Для эксперимента выбрали 14 поликонидиальных изолятов группы видов $A$. infectoria и моноконидиальные изоляты: вида A. tenuissima - 23, A. alternata - 20 и A. arborescens - 8, в числе последних 3 штамма из микологического гербария лаборатории микологии и фитопатологии им. А.А. Ячевского ВНИИ защиты растений (г. СанктПетербург), выделенные из ячменя (№№ 157011, 158011, 529051, Россия).

Для сравнения культурально-морфологических признаков изолятов, отнесенных к группе видов $A$. infectoria, использовали сахарозный агар с дрожжевым экстрактом (yeast extract sucrose agar, YES). Для посевов готовили 10-суточные культуры грибов на агаре Чапека-Докса. В качестве ростовых сред использовали картофельно-морковный агар (potato-carrot agar, PCA), сенной агар (hay infusion agar, HAY), приготовленные по описанным рецептурам (24), солодовый агар (MEA) (malt extract agar, «Liofilchem S.r.l.», Италия) и агар V-8 (vegetable juice agar), приготовленный по предложенной рецептуре (23) из овощного сока (ООО «Южная соковая компания», Краснодарский край, г. Белореченск, Россия). Инокулюм (в 3 повторностях) помещали во флаконы вместимостью 10 мл с диаметром дна около 18 мм, каждый из которых содержал по 1,5 мл одной их вышеназванных сред, флаконы закрывали ватно-марлевыми пробками, дополнительно обертывая слоем лабораторной пленки Parafilm M («Merck KGaA», Германия). Инкубировали в темноте 7 сут при $25^{\circ} \mathrm{C}$; в каждый флакон добавляли по 1,5 мл смеси ацетонитрила и воды в объемном соотношении 84:16 и интенсивно встряхивали в начале и конце стационарной 14-часовой экстракции. Анализ экстрактов на содержание АОЛ выполняли с помощью тест-системы для иммуноферментного определения альтернариола (25), предел детектирования токсина составил 0,01 мкг/г.

Данные обрабатывали с помощью описательной статистики в программе Microsoft Excel 2013, результаты выражали как средние арифметические полученных значений $(M)$ с ошибкой выборочной средней ( $\pm \mathrm{SEM})$.

Результаты. Согласно данным обширного изучения видового состава грибов Alternaria на европейской территории России, проведенного недавно, в семенах злаков наиболее распространены виды A. tenuissima и комплекс видов A. infectoria, тогда как A. alternata и A. arborescens выявляются заметно реже (26-28). Результаты первого обследования зерновых кормов определенно указывали на то, что в составе микобиоты зерна пшеницы и ячменя преобладает вид $A$. tenuissima (29).

Для выполнения работы из более чем 150 образцов зерновых кормов (главным образом, зерна пшеницы, ячменя, семян подсолнечника и комбикормов с высокой долей зерновых компонентов) нам удалось получить достаточные по объемам выборки изолятов только для A. tenuissima, A. alternata и группы видов A. infectoria. Изоляты, идентифицированные как $A$. arborescens, обнаружили только в 5 образцах, поэтому дополнительно были взяты близкие по происхождению коллекционные штаммы. Нам представлялось целесообразным провести тестирование изолятов на панели сред, рекомендованных для процедуры видовой идентификации, поскольку такой подход в перспективе мог быть использован для быстрого детектирования токсинообразования у этих грибов уже на стадии микологических посевов. Каждый из 66 штаммов выращивали в идентичных условиях на агарах PCA, MEA, НАY и V-8. Сравнительные испытания токсинообразования у изолятов A. tenuissima, A. alternata, A. arborescens и группы видов A. infectoria на РСА, 
НАY и V-8 впервые выполнены в этой работе.

1. Продуцирование альтернариола (АОЛ) моноконидиальными изолятами Alternaria tenuissima из образцов зерновых кормов на разных агаризованных средах (7 сут, $\left.25^{\circ} \mathrm{C}\right)(M \pm \mathrm{SEM})$

\begin{tabular}{l|c|c|c|c}
\hline \multirow{2}{*}{ Изолят, рег. №, $n=23$} & \multicolumn{3}{|c}{ Количество АОЛ, МКг/г субстрата } \\
\cline { 2 - 5 } & PСА & МЕА & НАY & V-8 \\
\hline $204 / 1$ & $0,04 \pm 0,01$ & $105 \pm 20$ & $26 \pm 3$ & $38 \pm 4$ \\
$215 / 1$ & $0,50 \pm 0,10$ & $22 \pm 4$ & $16 \pm 3$ & $23 \pm 2$ \\
$221 / 1$ & $0,07 \pm 0,00$ & $253 \pm 35$ & $37 \pm 7$ & $12 \pm 1$ \\
222 & $0,80 \pm 0,20$ & $138 \pm 18$ & $20 \pm 4$ & $72 \pm 12$ \\
225 & $2,90 \pm 0,40$ & $73 \pm 15$ & $37 \pm 6$ & $12 \pm 2$ \\
228 & - & $30 \pm 7$ & $4,8 \pm 0,6$ & $0,3 \pm 0,0$ \\
$233 / 1$ & $0,04 \pm 0,00$ & $10 \pm 2$ & $23 \pm 6$ & $80 \pm 14$ \\
$234 / 2$ & - & $33 \pm 3$ & $7,3 \pm 1,1$ & $117 \pm 23$ \\
$236 / 1$ & $0,02 \pm 0,00$ & $26 \pm 6$ & $59 \pm 8$ & $19 \pm 3$ \\
$241 / 1$ & $0,20 \pm 0,00$ & $200 \pm 43$ & $53 \pm 8$ & $37 \pm 7$ \\
$242 / 1$ & $0,90 \pm 0,20$ & $39 \pm 7$ & $1,5 \pm 0,3$ & $3,9 \pm 0,2$ \\
255 & $0,04 \pm 0,00$ & $5,5 \pm 0,7$ & $0,3 \pm 0,0$ & $12 \pm 2$ \\
$337 / 1$ & $0,04 \pm 0,00$ & $0,1 \pm 0,0$ & $0,1 \pm 0,0$ & $0,2 \pm 0,0$ \\
$342 / 1$ & $0,03 \pm 0,00$ & $58 \pm 8$ & $87 \pm 15$ & $120 \pm 25$ \\
$357 / 1$ & $0,06 \pm 0,01$ & $21 \pm 4$ & $4,7 \pm 0,9$ & $6,1 \pm 0,9$ \\
$359 / 1$ & $2,30 \pm 0,40$ & $100 \pm 18$ & $1,7 \pm 0,2$ & $19 \pm 2$ \\
$368 / 1$ & $50,00 \pm 8,00$ & $2,0 \pm 0,1$ & $0,2 \pm 0,0$ & $0,2 \pm 0,0$ \\
$372 / 1$ & $1,10 \pm 0,20$ & $31 \pm 5$ & $0,3 \pm 0,0$ & $2,7 \pm 0,5$ \\
$381 / 1$ & $0,20 \pm 0,00$ & $23 \pm 6$ & $9,2 \pm 1,4$ & $12 \pm 2$ \\
$384 / 1$ & $0,05 \pm 0,00$ & $5,8 \pm 0,9$ & $5,9 \pm 0,9$ & $3,6 \pm 0,7$ \\
392 & $0,10 \pm 0,00$ & $402 \pm 43$ & $69 \pm 13$ & $25 \pm 6$ \\
$395 / 1$ & $0,10 \pm 0,00$ & $3,7 \pm 0,6$ & $0,1 \pm 0,0$ & $13 \pm 2$ \\
397 & $0,20 \pm 0,00$ & $106 \pm 18$ & $0,5 \pm 0,1$ & $24 \pm 4$ \\
$n^{+}\left(n^{10} / n^{100}\right)$ & $21(0 / 0)$ & $23(17 / 7)$ & $23(10 / 0)$ & $23(16 / 2)$ \\
Диапазон & $0,02-2,90$ & $0,1-402$ & $0,08-87$ & $0,2-120$ \\
Среднее, $n^{+}$ & 0,5 & 73 & 20 & 28 \\
\hline 1 & и & 73 &
\end{tabular}

П р и м е ч а н и е. $n-$ число исследованных изолятов; $n^{+}-$число изолятов, продуцирующих АОЛ; $n^{10}-$ число изолятов, продуцирующих АОЛ в количествах $>10$ мкг $/ г ; n^{100}$ - число изолятов, продуцирующих АОЛ в количествах > 100 мкг/г; прочерк означает, что микотоксин не обнаружен (предел детектирования 0,01 мкг/г); PCA - potato-carrot agar (картофельно-морковный агар), МЕА - malt infusion agar (солодовый агар), НАY - hay infusion agar (сенной агар), V-8 - vegetable agar (овощной агар).

Все изоляты A. tenuissima на MEA, HАY и V-8 продуцировали АОЛ, а на РСА у двух изолятов токсин не обнаружили (табл. 1). На всех средах диапазоны колебаний количества токсина у изолятов составляли три порядка. Эту особенность мы отмечали и ранее, причем она была еще более выраженной - накопление АОЛ у 15 изолятов A. tenuissima (сусловый агар, 7 сут, $25^{\circ} \mathrm{C}$ ) характеризовалось значениями в пределах от 0,8 до 710 мкг/г (29). У 17 штаммов, выделенных из зерна в Новосибирской области (субстрат - рис, 14 сут, $25^{\circ} \mathrm{C}$ ), колебания были значительнее - от 0,405 до 26900 мкг/г (14). Реакция на тип питательной среды у изолятов A. tenuissima имела групповой характер. Преимушественное накопление на МЕА обнаружили у 12 из них, на V-8 - у 5, еще 5 продуцировали сопоставимые количества на всех трех субстратах. В среднем по всей выборке интенсивность накопления АОЛ снижалась в ряду МЕА > V-8 > НАҮ. Содержание токсина 10 мкг/г и более выявили на MEA у 17 культур, на V-8 - у 16, на НАY - у 10. Сверхактивное продуцирование (свыше 100 мкг/г) отмечали на MEA и V-8 соответственно у 7 и 2 изолятов, но на НАY его не наблюдали. В целом, судя по средним значениям для всей выборки, наибольший метаболический ответ у A. tenuissima достигался на MEA, на HAY и V-8 он был несколько ниже.

Как следует из данных, представленных в таблице 2, у A. alternata диапазон колебаний количеств АОЛ на МЕА и V-8 составил 4 и 5 порядков. Столь же широким он был у единичных обследованных штаммов A. alternata (рис, 14 сут, $25^{\circ} \mathrm{C}$ ) из зерна в Новосибирской области (14). Токсин не обнаружили у 4 изолятов на РСА (№№ 223/2, 380/1, 385/1 и 388/1), у 3 - на 
HAY (№№ 216/2, 388/1 и 418/4) и у двух - на V-8 (№№ 216/2 и 418/4). При диапазоне от 0,03 до 5,3 мкг/г средняя величина по выборке (1,3 мкг/г) на РСА была существенно ниже, чем на остальных питательных средах.

2. Продуцирование альтернариола (АОЛ) моноконидиальными изолятами Alternaria alternata из образцов зерновых кормов на разных агаризованных средах (7 сут, $\left.25^{\circ} \mathrm{C}\right)(M \pm \mathrm{SEM})$

\begin{tabular}{|c|c|c|c|c|}
\hline \multirow{2}{*}{ Изолят, рег. №, $n=20$} & \multicolumn{4}{|c|}{ Количество АОЛ, мкг/г субстрата } \\
\hline & PCA & MEA & HAY & $\mathrm{V}-8$ \\
\hline 210 & $0,3 \pm 0,0$ & $155 \pm 24$ & $100 \pm 20$ & $267 \pm 38$ \\
\hline $216 / 2$ & $2,2 \pm 0,3$ & $2,8 \pm 0,4$ & - & - \\
\hline 219 & $0,6 \pm 0,1$ & $3,1 \pm 0,5$ & $2,8 \pm 0,5$ & $2,8 \pm 0,4$ \\
\hline 220 & $0,1 \pm 0,0$ & $125 \pm 25$ & $23 \pm 4$ & $89 \pm 10$ \\
\hline $223 / 2$ & - & $272 \pm 38$ & $1,9 \pm 0,3$ & $3,5 \pm 0,5$ \\
\hline $227 / 1$ & $3,3 \pm 0,7$ & $133 \pm 30$ & $10 \pm 2$ & $19 \pm 3$ \\
\hline $233 / 2$ & $0,4 \pm 0,1$ & $114 \pm 20$ & $25 \pm 4$ & $13 \pm 2$ \\
\hline $235 / 2$ & $0,1 \pm 0,0$ & $130 \pm 30$ & $70 \pm 12$ & $70 \pm 10$ \\
\hline $238 / 1$ & $0,3 \pm 0,0$ & $6,5 \pm 1,2$ & $27 \pm 6$ & $10 \pm 2$ \\
\hline $342 / 2$ & $0,03 \pm 0,01$ & $3,3 \pm 0,6$ & $8,9 \pm 1,3$ & $2,0 \pm 0,2$ \\
\hline $358 / 1$ & $0,5 \pm 0,1$ & $20 \pm 3$ & $11 \pm 2$ & $38 \pm 3$ \\
\hline $377 / 1$ & $0,9 \pm 0,2$ & $10 \pm 2$ & $14 \pm 3$ & $14 \pm 3$ \\
\hline $380 / 1$ & - & $0,2 \pm 0,0$ & $0,3 \pm 0,1$ & $0,4 \pm 0,1$ \\
\hline $383 / 1$ & $0,1 \pm 0,0$ & $43 \pm 7$ & $35 \pm 7$ & $50 \pm 9$ \\
\hline $385 / 1$ & - & $246 \pm 39$ & $71 \pm 15$ & $365 \pm 43$ \\
\hline $388 / 1$ & - & $0,04 \pm 0,01$ & - & $0,07 \pm 0,01$ \\
\hline $390 / 1$ & $0,6 \pm 0,2$ & $80 \pm 15$ & $57 \pm 10$ & $461 \pm 70$ \\
\hline $396 / 1$ & $2,2 \pm 0,4$ & $72 \pm 10$ & $48 \pm 8$ & $19 \pm 3$ \\
\hline 399 & $3,6 \pm 0,8$ & $7,0 \pm 1,3$ & $53 \pm 8$ & $40 \pm 8$ \\
\hline $418 / 4$ & $5,3 \pm 1,2$ & $0,1 \pm 0,0$ & - & - \\
\hline$n^{+}\left(n^{10} / n^{100}\right)$ & $16(0 / 0)$ & $20(12 / 7)$ & $17(13 / 0)$ & $18(12 / 3)$ \\
\hline Диапазон & $0,03-5,3$ & $0,04-272$ & $0,3-100$ & $0,07-267$ \\
\hline Среднее, $n^{+}$ & 1,3 & 71 & 33 & 81 \\
\hline \multicolumn{5}{|c|}{$\begin{array}{l}\text { П р и м е ч а н и е. } n-\text { число исследованных изолятов; } n^{+}-\text {число изолятов, продуцирующих АОЛ; } n^{10}- \\
\text { число изолятов, продуцирующих АОЛ в количествах }>10 \text { мкг/г; } n^{100}-\text { число изолятов, продуцирующих } \\
\text { АОЛ в количествах }>100 \text { мкг/г; прочерк означает, что микотоксин не обнаружен (предел детектирования - } \\
0,01 \text { мкг/г); PCA - potato-carrot agar (картофельно-морковный агар), MEA - malt infusion agar (солодовый } \\
\text { агар), НАY - hay infusion agar (cенной агар), V-8 - vegetable agar (овощной aгар). }\end{array}$} \\
\hline
\end{tabular}

Интенсивность токсинообразования была сравнимой на V-8 и МЕA (соответственно 81 и 71 мкг/г) и несколько меньшей - на НАY (33 мкг/г). На РСА продуцентов с высокой активностью вообще не выявили, тогда как на остальных трех средах накоплением АОЛ более 10 мкг/г характеризовались по 12-13 изолятов. Сверхвысокую активность, соответствующая количествам 100 мкг/г и более, не наблюдали на НАY, но установили на V-8 для 3 изолятов и на МЕА - для 7 изолятов.

У A. alternata, как и у A. tenuissima, по реакции на состав среды наблюдалось распределение на группы - с преимущественным накоплением на МЕА (6 изолятов), на НАY (2 изолята с количествами, сопоставимыми с таковыми на МЕA) и V-8 (3 изолята), а также на всех трех средах (5 изолятов). Отмечались лишь единичные изоляты с продуцированием наибольших количеств токсина на V-8 (№ 390/1) и с примерно равным накоплением АОЛ на РСА и МЕА (№ 216/2). Аномальная реакция с наибольшим накоплением на РСА показана у изолята № 418/4 из зерна ячменя. В целом, самый интенсивный метаболический ответ у A. alternata достигался на средах MEA и V-8. Более выраженный синтез АОЛ на этих двух средах в сравнении с солодовым агаром (WA) и сахарозным агаром с дрожжевым экстрактом (YES) был ранее показан нами для некоторых штаммов, идентифицированных как A. tenuissima и A. alternata (30).

Несмотря на явные различия реакций на тип среды, субстратных профилей токсинообразования и широты диапазона количеств АОЛ у представителей A. tenuissima и A. alternata (см. табл. 1, 2), оценка по общему числу продуцентов и доле высокоактивных и сверхактивных изолятов 
показывает, что наибольшая степень реализации биосинтетического потенциала A. tenuissima и A. alternata по АОЛ происходит на МЕА. Суммарная величина накопления АОЛ в этих условиях для обоих видов оказалась практически одинаковой и составила соответственно 73 и 71 мкг/г.

3. Продуцирование альтернариола (АОЛ) моноконидиальными изолятами Alternaria arborescens из образцов зерновых кормов на разных агаризованных средах $\left(7\right.$ сут, $\left.25^{\circ} \mathrm{C}\right)(M \pm \mathrm{SEM})$

\begin{tabular}{|c|c|c|c|c|}
\hline \multirow{2}{*}{ Изолят, рег. №, $n=8$} & \multicolumn{4}{|c|}{ Количество АОЛ, мкг/г субстрата } \\
\hline & PCA & MEA & HAY & $\mathrm{V}-8$ \\
\hline $3 / 3$ & $1,9 \pm 0,3$ & $79 \pm 14$ & $117 \pm 22$ & $173 \pm 30$ \\
\hline $15 / 6$ & $1,5 \pm 0,3$ & $10 \pm 2$ & $11 \pm 3$ & $20 \pm 6$ \\
\hline $19 / 4$ & $0,8 \pm 0,1$ & $4,4 \pm 0,5$ & $47 \pm 11$ & $8,8 \pm 1,6$ \\
\hline $39 / 4$ & $0,9 \pm 0,1$ & $4,0 \pm 0,5$ & $6,8 \pm 1,2$ & $13 \pm 4$ \\
\hline $338 / 1$ & $1,5 \pm 0,2$ & $77 \pm 13$ & $133 \pm 20$ & $12 \pm 2$ \\
\hline 157011 & $1,9 \pm 0,3$ & $69 \pm 14$ & $113 \pm 17$ & $129 \pm 25$ \\
\hline 158011 & $1,3 \pm 0,2$ & $2,0 \pm 0,2$ & $69 \pm 13$ & $488 \pm 38$ \\
\hline 529051 & $0,9 \pm 0,2$ & $6,7 \pm 1,3$ & $11 \pm 2$ & $4,3 \pm 0,8$ \\
\hline$n^{+}\left(n^{10} / n^{100}\right)$ & $8(0 / 0)$ & $8(3 / 0)$ & $8(7 / 3)$ & $8(6 / 3)$ \\
\hline Диапазон & $0,8-1,9$ & $2,0-79$ & $6,8-133$ & $4,3-488$ \\
\hline Среднее, $n^{+}$ & 1,3 & 31 & 64 & 106 \\
\hline
\end{tabular}

П р и м е ч а н и е. $n$ - число исследованных изолятов; $n^{+}-$число изолятов, продуцирующих АОЛ; $n^{10}-$ число изолятов, продуцирующих АОЛ в количествах $>10$ мкг $/ г ; n^{100}$ - число изолятов, продуцирующих АОЛ в количествах > 100 мкг/г; прочерк означает, что микотоксин не обнаружен (предел детектирования 0,01 мкг/г); PCA - potato-carrot agar (картофельно-морковный агар), МЕА - malt infusion agar (солодовый агар), HAY - hay infusion agar (сенной агар), V-8 - vegetable agar (овощной агар).

Изоляты A. arborescens продуцировали АОЛ на всех средах (табл. 3), но у них его количество варьировало значительно меньше, чем у двух описанных выше видов (см. табл. 1, 2), и составляло 1-2 порядка. Однако доступный объем выборки заметно уступал таковому для A. tenuissima и A. alternata, поэтому констатация этого факта возможна, но прямое сравнение вряд ли корректно. Действительно, для A. arborescens описаны случаи значительных колебаний - например, для единичных штаммов из зерна в Новосибирской области диапазон колебаний количества АОЛ был чрезвычайно широким (14). В то же время ранее при тестировании трех штаммов этого вида, выделенных из зерна кукурузы и семян подсолнечника, интенсивность продуцирования АОЛ на MEA (3,3-36 мкг/г) была вполне сопоставимой с колебаниями в пределах одного порядка (31).

Среди изолятов встречались варианты с наибольшей продукцией АОЛ на НАY и V-8, а также на НАY и MEA. Хотелось бы отметить, что аномальные реакции на тип среды также возможны - для коллекционного штамма A. arborescens № 100041, выделенного в 2007 году из листьев пшеницы в Сирии, показано снижение количеств АОЛ в ряду РСА > MEA > НАY, V-8 от $15 \pm 3$ до $0,03 \pm 0,01$ мкг/г (неопубликованные данные авторов). Таким же типом метаболического ответа характеризовался штамм A. alternata № 418/4, который мы выделили из зерна ячменя (см. табл. 2). В целом по выборке наибольшую продукцию АОЛ отмечали на средах V-8, НАY и MЕА. Суммарное накопление АОЛ в этих условиях составило соответственно 106, 64 и 31 мкг/г.

Разнонаправленные смещения интенсивности биосинтеза АОЛ на панели ростовых сред, которые наблюдались у изолятов всех трех видов, возможно, связаны с внутривидовыми индивидуальными или групповыми особенностями функционирования геномного аппарата при участии регуляторов метаболических процессов. Более детальное изучение этой проблемы представляет особую ценность для развития хемотаксономии грибов Alternaria, которой в последние годы уделяется все большее внимание (3234). Результаты экспериментов, в которых показано преимущество использования коммерческого субстрата МЕА, а также двух других микологических 
сред V-8 и НАY, имеет важное значение для совершенствования лабораторных приемов изучения биосинтетических возможностей этих микроскопических грибов, которое было начато в 1990 -е годы $(35,36)$ и продолжает обсуждаться в научной литературе $(14,37)$.

Все изоляты грибов, которые на 10 -е сут роста при $25{ }^{\circ} \mathrm{C}$ на среде YES образовывали слабоокрашенный воздушный мицелий и колонии разной структуры и плотности, были отнесены к группе видов A. infectoria. Для 13 из них отчетливо прослеживалось сходство по культурально-морфологическим признакам (при небольших различиях). Диаметр колонии составлял 45-60 мм, структура воздушного мицелия была преимущественно ватообразной (от разреженной до более плотной), в его окраске преобладал белорозовый тон с вкраплениями серого, бежевого или оливково-серого цвета, обратная сторона колонии была светло-коричневой или темно-коричневой, в основном с радиальными бороздами. При тестировании культур с такими характеристиками на всей панели ростовых сред не удалось обнаружить АОЛ, и этот результат соответствовал полученному ранее на единичных изолятах (25). Однако одна из культур - A. infectoria № 6/10 заметно отличалась от остальных скоростью роста (диаметр колонии 80 мм), низким, относительно плотным, слегка тяжистым воздушным мицелием светло-бежевого цвета с сектором (20 мм) розового цвета, обратная сторона колонии имела светло-коричневую окраску с радиальными бороздами, в области сектора - светло-оранжевую (рис.). Этот изолят оказался активным продуцен-

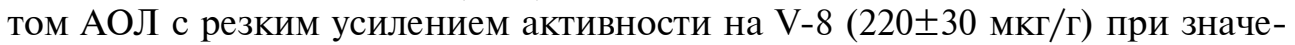
ниях $2,0 \pm 0,2 ; 14 \pm 3$ и $18 \pm 4$ мкг/г соответственно на РСА, МЕА и НАY. Подобную реакцию на смену ростовой среды мы также отмечали у некоторых представителей A. alternata и A. tenuissima (см. табл. 1, 2). По данным немецких исследователей, два изолята A. infectoria из зерна в Новосибирской области тоже продуцировали АОЛ в контрастных количествах - крайне малом и сверхвысоком (14). Интересно, что недавно при исследовании группы видов A. infectoria на модифицированной среде YES были выявлены два морфологических типа, различающихся пигментацией (38), однако, к сожалению, оценка способности к токсинообразованию для них не проводилась.
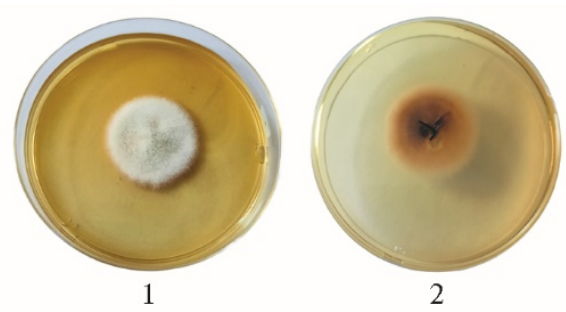

Макроскопические характеристики изолята группы видов $\boldsymbol{A}$. infectoria № 6/10 (сахарозный агар с дрожжевым экстрактом, yeast extract sucrose agar, YES, 10 сут, $25^{\circ} \mathrm{C}$ ): $1-$ вид колонии сверху, 2 - обратная сторона колонии.

Вопрос о способности A. infectoria продуцировать АОЛ пока остается открытым (1). В большинстве публикаций сообщается, что его образование не свойственно этой группе видов (18), однако в нескольких работах среди изолятов найдены токсиногенные продуценты $(14,16,34)$. Согласно последним данным, указанной группе присуще образование токсинов другого структурного ряда - периленхинонов $(14,16)$.

По совокупной оценке на основании ряда показателей, для A. tenuissima, A. alternata и A. arborescens, встречающихся в зерновых кормах, в настоящей работе нами представлено экспериментальное подтверждение выраженной и практически одинаковой способности продуцировать АОЛ. Эти результаты в целом соответствуют полученным ранее на единичных представителях этих видов (29-31), а также согласуется с данными зарубежных исследователей для видов, встречающихся в зерне и зернопродукции в Аргентине, Бразилии (7-9), странах Средиземноморья, Словакии, Италии $(10,11,39)$ и Корее (13). 
Использованный нами принцип формирования выборки культур для тестирования по варианту 1 изолят - 1 проба позволяет впервые сделать вывод о высоком токсигенном потенциале популяций трех мелкоспоровых видов - A. tenuissima, A. alternata и A. arborescens и их причастности к контаминации АОЛ зерновых кормов. Согласно недавним сведениям, в нашей стране проблема контаминации этим токсином в последние годы приобретает особую актуальность для фуражного зерна кукурузы (40) и комбикормов на зерновой основе (41).

Таким образом, установлено, что среди грибов рода Alternaria, представленных в зерновых кормах, популяции трех морфологических видов A. tenuissima A. alternata и A. arborescens способны к активному продуцированию альтернариола (для большинства изолятов характерно накопление количеств свыше 10 мкг/г ростовой среды) и могут иметь отношение к контаминации этих биообъектов, а вклад группы видов A. infectoria оценен как маловероятный. Дальнейшее развитие популяционного подхода, использованного в представленной работе, имеет важное значение для совершенствования приемов оценки рисков загрязнения кормовой продукции токсикантами микогенного происхождения. Успешное применение типовых микологических сред для экспресс-тестирования изолятов in vitro подтверждает возможность совместить контроль потенциала их токсинообразования с процедурой видовой идентификации. Данные о соответствиях между культурально-морфологическими признаками и филогенетическим положением этих грибов, с одной стороны, и форматом синтеза их токсичных вторичных метаболитов, - с другой, остается ключевой составляющей общей информационной базы, активно формируемой в последние годы для уточнения систематики рода Alternaria.

\section{ЛИТЕРАТУРА}

1. Tralamazza S.M., Piacentini K.C., Iwase C.H.T., De Oliveira Rocha L. Toxigenic Alternaria species: impact in cereals worldwide. Current Opinion in Food Science, 2018, 23: 57-63 (doi: 10.1016/j.cofs.2018.05.002).

2. Ostry V. Alternaria mycotoxins: an overview of chemical characterization, producers, toxicity, analysis and occurrence in foodstuffs. World Mycotoxin Journal, 2008, 1(2): 175-188 (doi: 10.3920/WMJ2008.x013).

3. EFSA on Contaminants in the Food Chain (CONTAM). Scientific opinion on the risks for animal and public health related to the presence of Alternaria toxins in feed and food. EFSA Journal, 2011, 9(10): 2407 (doi: 10.2903/j.efsa.2011.2407).

4. Lou J., Fu L., Peng Y., Zhou L. Metabolites from Alternaria fungi and their bioactivities. Molecules, 2013, 18(5): 5891-5935 (doi: 10.3390/molecules18055891).

5. Lee H.B., Patriarca A., Magan N. Alternaria in food: ecophysiology, mycotoxin production and toxicology. Mycobiology, 2015, 43(2): 93-106 (doi: 10.5941/MYCO.2015.43.2.93).

6. Mao Z., Sun W., Fu L., Luo H., Lai D., Zhou L. Natural dibenzo- $\alpha$-pyrones and their bioactivities. Molecules, 2014, 19(4): 5088-5108 (doi: 10.3390/molecules19045088).

7. Patriarca A., Azcarate M.P., Terminiello L., Fernández Pinto V. Mycotoxin production by Alternaria strains isolated from Argentinian wheat. International Journal of Food Microbiology, 2007, 119(3): 219-222 (doi: 10.1016/j.ijfoodmicro.2007.07.055).

8. Mašková Z., Tančinová D., Barboráková Z., Felšöciová S., Cisarová M. Comparison of occurrence and toxinogenity of Alternaria spp. isolated from samples of conventional and new crossbred wheat of Slovak origin. Journal of Microbiology, Biotechnology and Food Sciences, 2012, 1(4): 552-562 (doi: 10.15414 /jmbfs.2016.5.6.552-556).

9. Oviedo M.S., Sturm M.E., Reynoso M.M., Chulze S.N., Ramirez M.L. Toxigenic profile and AFLP variability of Alternaria alternata and Alternaria infectoria occurring on wheat. Brazilian Journal of Microbiology, 2013, 44(2): 447-455 (doi: 10.1590/S1517-83822013000200017).

10. Andersen B., Nielsen K.F., Fernández Pinto V., Patriarca A. Characterization of Alternaria strains from Argentinean blueberry, tomato, walnut and wheat. International Journal of Food Microbiology, 2015, 196: 1-10 (doi: 10.1016/j.ijfoodmicro.2014.11.029).

11. Ramires F.A., Masiello M., Somma S., Villani A., Susca A., Logrieco A.F., Luz C., Meca G., Moretti A. Phylogeny and mycotoxin characterization of Alternaria species isolated from wheat grown in Tuscany, Italy. Toxins, 2018, 10(11): 472 (doi: 10.3390/toxins10110472). 
12. Li F., Toyazaki N., Yoshizawa T. Production of Alternaria mycotoxins by Alternaria alternata isolated from weather-damaged wheat. Journal of Food Protection, 2001, 64(4): 567-571 (doi: $10.4315 / 0362-028 \mathrm{x}-64.4 .567)$.

13. Nguyen T.T.T., Kim J., Jeon S.J., Lee C.W., Magan N., Lee H.B. Mycotoxin production of Alternaria strains isolated from Korean barley grains determined by LC-MS/MS. International Journal of Food Microbiology, 2018, 268: 44-52 (doi: 10.1016/j.ijfoodmicro.2018.01.003).

14. Zwickel T., Kahr S.M., Rychlik M., Müller E.H. Chemotaxonomy of mycotoxigenic small-spored Alternaria fungi - do multitoxin mixtures act as an indicator for species differentiation? Frontiers in Microbiology, 2018, 9: 1368 (doi: 10.3389/fmicb.2018.01368).

15. Andersen B., Thrane U. Secondary metabolites produced by Alternaria infectoria and their use as chemotaxonomic markers. Mycotoxin Research, 1996, 12(2): 54-60 (doi: 10.1007/BF03192262).

16. Andersen B., Thrane U. Differentiation of Alternaria infectoria and Alternaria alternata based on morphology, metabolite profiles, and cultural characteristics. Canadian Journal of Microbiology, 1996, 42(7): 685-689 (doi: 10.1139/m96-093).

17. Andersen B., Krøger E., Roberts R.G. Chemical and morphological segregation of Alternaria alternata, A. gaisen and A. longipes. Mycological Research, 2001, 105(3): 291-299 (doi: 10.1017/S0953756201003446).

18. Pinto V.F., Patriarca A. Alternaria species and their associated mycotoxins. In: Mycotoxigenic Fungi: Methods in Molecular Biology, vol. 1542 /A. Moretei, A. Susca (eds.). Humana Press, New York, NY, 2017: 13-32 (doi: 10.1007/978-1-4939-6707-0_2).

19. Lawrence D.P., Rotondo F., Gannibal P.B. Biodiversity and taxonomy of the pleomorphic genus Alternaria. Mycological Progress, 2016, 15(1): article 3 (doi: 10.1007/s11557-015-1144-x).

20. Gannibal Ph.B., Yli-Mattila T. Cultural and molecular differentiation of small-spored Alternaria species associated with Роасеае. Микология и фитопатология, 2005, 39(4): 13-23.

21. Frisvad J.C., Smedsgaard J., Larsen T.O., Samson R.A. Mycotoxins, drugs and other extrolites produced by species in Penicillium subgenus Penicillium. Studies in Mycology, 2004, 49: 201-241.

22. Frisvad J.C., Hubka V., Ezekiel C.N., Hong S.-B., Nováková A., Chen A.J., Arzanlou M., Larsen T.O., Sklenár F., Mahakarnchanakul W., Samson R.A., Houbraken J. Taxonomy of Aspergillus section Flavi and their production of aflatoxins, ochratoxins and other mycotoxins. Studies in Mycology, 2019, 93: 1-63 (doi: 10.1016/j.simyco.2018.06.001).

23. Simmons E.G. Alternaria. An identification manual. CBS, Utrecht, 2007.

24. Introduction to food- and airborne fungi /R.A. Samson, E.S. Hoekstra, J.S. Frisvad, O. Filtenborg (eds.). CBS, Utrecht, 2000.

25. Буркин А.А., Кононенко Г.П. Иммуноферментный анализ альтернариола. Иммунопатология, аллергология, инфектология, 2009, 2: 7-8.

26. Ганнибал Ф.Б. Мелкоспоровые виды рода Alternaria на злаках. Микология и фитопатология, 2004, 38(3): 19-28.

27. Ганнибал Ф.Б. Виды рода Alternaria в семенах зерновых культур в России. Микология и фитопатология, 2008, 42(4): 359-368.

28. Гагкаева Т.Ю., Ганнибал Ф.Б., Гаврилова О.П. Зараженность зерна пшеницы грибами Fusarium и Alternaria на юге России в 2010 году. Защита и карантин растений, 2012, 1: 37-42.

29. Пирязева Е.А., Кононенко Г.П. Продуцирование альтернариола отдельными видами $\mathrm{Al}$ ternaria из кормовых объектов. Мат. четвертого съезда микологов России «Современная микология в России», T. 7. М., 2017: 175-177.

30. Ustyuzhanina M.I., Burkin A.A., Kononenko G.P., Piryazeva E.A., Zotova E.V. Alternative assay media for alternariol production by Alternaria species. Proc. of the VIII International Conference on Environmental, Industrial and Applied Microbiology - BioMicroWorld2018 «Global progress in applied microbiology: a multidisciplinary approach»/A. Méndez-Vilas (ed.). Formatex Research Center, Badajoz, Spain, 2018: 1-5.

31. Kononenko G.P., Ustyuzhanina M.I., Orina A.S. Multi-substrate screening the ability to produce alternariol among Alternaria arborescens strains. Journal of Veterinary Science \& Technology, 2019, 10: 41-42.

32. Andersen B., Krøger E., Roberts G. Chemical and morphological segregation of Alternaria arborescens, A. infectoria and A. tenuissima species-groups. Mycological Research, 2002, 106(2): 170 182 (doi: 10.1017/S0953756201005263).

33. Andersen B., Sørensen J.L., Nielsen K.F., van den Ende B.G., de Hoog S. A polyphasic approach to the taxonomy of the Alternaria infectoria species-group. Fungal Genetics and Biology, 2009, 46: 642-656 (doi: 10.1016/j.fgb.2009.05.005).

34. Patriarca A., da Cruz Cabral L., Pavicich M.A., Nielsen K.F., Andersen B. Secondary metabolite profiles of small-spored Alternaria support the new phylogenetic organization of the genus. International Journal of Food Microbiology, 2019, 291: 135-143 (doi: 10.1016/j.ijfoodmicro.2018.11.022).

35. Kostecki M., Grabarkiewicz-Szczessna J., Chelkowski J. Biosynthesis and preparation of five $\mathrm{Al}$ ternaria metabolites. Mycotoxin Research, 1991, 7(1): 3-7 (doi: 10.1007/BF03192156).

36. Häggblom P., Hiltunen M. Regulation of mycotoxin biosynthesis in Alternaria. Mycotoxin Research, 1991, 7(1): 8-10 (doi: 10.1007/BF03192157).

37. Oviedo M.S., Ramirez M.L., Barros G.G., Chulze S.N. Impact of water activity and temperature on growth and alternariol and alternariol monomethyl ether production of Alternaria alternata isolated from soybean. Journal of Food Protection, 2010, 73(2): 336-343 (doi: 10.4315/0362-028X-73.2.336). 
38. Kosiak B., Torp M., Skjerve E., Andersen B. Alternaria and Fusarium in Norwegian grains of reduced quality - a matched pair sample study. International Journal of Food Microbiology, 2004, 93(1): 51-62 (doi: 10.1016/j.ijfoodmicro.2003.10.006).

39. Logrieco A., Bottalico A., Solfrizzo M., Mulé G. Incidence of Alternaria species in grains from Mediterranean countries and their ability to produce mycotoxins. Mycologia, 1990, 82(4): 501505 (doi: 10.2307/3760022).

40. Кононенко Г.П., Буркин А.А., Зотова Е.В., Смирнов А.М. Микотоксикологическое исследование кормового зерна кукурузы (1998-2018 гг.). Российская сельскохозяйственная наука, 2019, 3: 28-31 (doi: 10.31857/S2500-26272019328-31).

41. Кононенко Г.П., Буркин А.А., Зотова Е.В. Микотоксикологический мониторинг. Сообщение I. Полнорационные комбикорма для свиней и птицы (2009-2018 гг.). Ветеринария сегодня, 2020, 1(32): 60-65 (doi: 10.29326/2304-196X-2020-1-32-60-65).

\title{
Всероссийский НИИ ветеринарной санитарии, гигиены и экологии - филиал ФГБНУ ФНЦ ВИЭВ РАН, 123022 Россия, г. Москва, Звенигородское ш., 5, e-mail: kononenkogp@mail.ru $\bowtie$, piryazeva01@yandex.ru, aaburkin@mail.ru
}

\section{PRODUCTION OF ALTERNARIOL IN THE POPULATIONS OF GRAIN FEED-ASSOCIATED SMALL SPORE Alternaria SPECIES}

\section{G.P. Kononenko, E.A. Piryazeva, A.A. Burkin}

\begin{abstract}
All-Russian Research Institute for Veterinary Sanitation, Hygiene and Ecology - Branch of FSC ARRIEV RAS, 5, Zvenigorodskoe sh., Moscow, 123022 Russia, e-mail kononenkogp@mail.ru ( $\square$ corresponding author), piryazeva01@yandex.ru, aaburkin@mail.ru
\end{abstract}

ORCID:

Kononenko G.P. orcid.org/0000-0002-9144-615X

Piryazeva E.A. orcid.org/0000-0001-5443-3213

The authors declare no conflict of interests

Received February 18, 2020

Burkin A.A. orcid.org/0000-0002-5674-2818

doi: 10.15389 /agrobiology.2020.3.628eng

\section{Abstract}

Modern science has strong evidence that Alternaria fungi pose a serious toxic hazard. Alternaria species can grow well on various substrates and in a wide range of temperatures and humidity, occupying different ecological niches in this way, and can produce several types of especially dangerous secondary metabolites (S.M. Tralamazza et al., 2018). The most well-studied Alternaria mycotoxin alternariol $(\mathrm{AOH})$, a dibenzo- $\alpha$-pyron derivative, exhibits high cytotoxicity, genotoxic and mutagenic effects (Z. Mao et al., 2014). However, the ability of Alternaria fungi to produce this toxin still remains poorly studied. In Russia, a significant prevalence of small spore Alternaria species on grain crops (Ph.B. Gannibal, 2004, 2006; T.Yu. Gagkaeva et al., 2012), and an increase in the frequency of Alternaria occurrence and $\mathrm{AOH}$ accumulation in grain and feed mixtures (G.P. Kononenko et al., 2019, 2020) have been recently reported. In this article, we first showed that the species A. tenuissima, A. alternata, and $A$. arborescens can cause $\mathrm{AOH}$ contamination of grain feeds. The work aims to investigate $\mathrm{AOH}$ production by the grain feed-associated Alternaria species. Alternaria fungi were isolated from 57 feed samples of different types (wheat, barley, corn and oats, sunflower seeds, wheat bran and mixed feeds). Monoconidial isolates identified by morpho-cultural features as A. tenuissima (Nees et T. Nees: Fries) Wiltshire, A. alternata (Fr.) Keissl, and A. arborescens E.G. Simmons, and another 14 isolates assigned to A. infectoria species group were cultured for 7 days at $25{ }^{\circ} \mathrm{C}$ on a panel of 4 mycological media, the potato-carrot agar (PCA), hay infusion agar (HAY), malt extract agar (MEA), and vegetable juice agar (V-8). AOH was detected in extracts using a certified commercial kit for indirect competitive enzyme-linked immunosorbent assay (ELISA). Among the isolates belonging to $A$. infectoria species group, 13 were devoid of producing ability while for one of them the accumulation of $\mathrm{AOH}$ was observed on all growth media in quantities $2.0 \pm 0.2,14 \pm 3,18 \pm 4$ and $220 \pm 30 \mu \mathrm{g} / \mathrm{g}$, respectively. Evaluation of the biosynthetic potential of $A$. tenuissima and A. alternata showed the highest degree of its realization on MEA growth medium in terms of the total number of producers and the share of highly active and superactive isolates. The total amount of $\mathrm{AOH}$ accumulation in these conditions for both species was almost the same and amounted to 73 and $71 \mu \mathrm{g} / \mathrm{g}$, respectively. A. arborescens isolates provided the highest $\mathrm{AOH}$ production on $\mathrm{V}-8$, HAY, and MEA media in amounts equal to 106,64 , and $31 \mu \mathrm{g} / \mathrm{g}$, respectively. The peculiarities of metabolic response of $A$. tenuissima, $A$. alternata and $A$. arborescens species to environmental changes and a rapid method to assess toxigenicity of Alternaria fungi during taxonomic identification are discussed.

Keywords: alternariol, Alternaria tenuissima, Alternaria alternata, Alternaria arborescens, Alternaria infectoria species group, grain feeds, ELISA. 